\title{
Notas sobre el pensamiento mítico
}

El estudio del mito, o del pensamiento mítico si se quiere, descansa en una profunda incomprensión en lo que toca a su carácter funcional, para no hablar de sus aspectos más generales. En términos amplios, la interpretación del mito se orienta hacia una reducción o hacia una racionalización que tiende a desarticularlo o a desmontarlo metódicamente hasta llegar al resultado de que se tiene la certeza de saber lo que quiere decir. Este proceso tiene como base una línea de pensamiento racionalista cartesiana - uno de los soportes de la cultura occidental - acentuada en los tiempos recientes con el desarrollo de la racionalidad tecnológica, la cual, dicho sea de paso, no constituye sino otro mito cuya finalidad es la destrucción de todos los mitos anteriores.

In estas notas me propongo explorar algunas aportaciones de la mitología (en el sentido etimológico del término) contemporánea acerca de la interpretación general del mito y de su función. Godelier, por ejemplo, estudioso marxista de la antropología, resuelve la cuestión de manera sencilla: para él, los mitos son "una representación ilusoria del hombre y del mundo, una explicación inexacta del orden de las cosas". Con esta concepción el problema se desplaza, puesto que si se sabe lo que es el mito, queda la duda de saber cómo se forma, es decir, cómo es que ciertos materiales objetivos de la realidad social, por el solo hecho de formar parte de un discurso mítico, "adoptan un carácter fantasmagórico, transformándose en representación ilusoria del mundo". (1980:370). La respuesta que aventura el autor. es un silogismo perfecto: si el pensamiento mítico es un pensamiento que concibe la realidad por 
analogía y si la analogía engendra una representación ilusoria del mundo, entonces el pensamiento mítico es una representación ilusoria del mundo (Ibid). La argumentación es la siguiente: la experiencia humana se divide en dos campos: lo que está bajo. el control del hombre, ya sea en el mundo de la naturaleza o en el de la cultura, y lo que no estábajo su control. Obviamente tal división es distinta en cada forma de sociedad y en cada época histórica. El dominio de lo no controlado se presenta como un conjunto de fuerzas superiores que el hombre necesita representarse y_explicar; en otras palabras, requiere tener un control, aunque sea indirecto, sobre ellas. No obstante, el hecho que se presente como un conjunto de fuerzas superiores no produce automáticamente una representación ilusoria; al contrario, estas fuerzas son datos objetivos de la realidad. La tesis de Godelier es que sólo a partir del momento en que esas realidades se presentan como seres análogos al hombre, cuando las causas que regulan el mundo natural y cultural se consideran como dotados de conciencia, voluntad y poder, sólo entonces tales datos se convierten en representaciones ilusorias. Sin embargo, tal analogía no es perfecta puesto que esas representaciones difieren del hombre en que hacen y saben lo que éste no puede hacer ni saber; por tanto, en que son superiores. Este es el origen de los personajes míticos según Godelier y una buena parte de los pensadores contemporáneos. La conclusión obligada de este razonamiento es que, a medida que el conocimiento humano avan$\mathrm{za}$, los sectores de la realidad que no tienen una explicación racional tienden a disminuir $y$, en el límite, no existirian zonas oscuras y, por tanto, el pensamiento mítico no tendría razón de ser. Esta conclusión parece ahora difícil de aceptar, incluso para los etnólogos marxistas. Por otro laclo, la respuesta de Godelier a las preguntas esenciales respecto a la funcionalidad del mito (epara qué sirven los mitos, qué papel desempeñan, cuál es la naturaleza de su función social en una cultura dada?), se reduce a una sola: a través del mito,... el hombre 
personifica las potencias desconocidas y con ello las hace manejables.

A pesar de los planteamientos anteriormente señalados, tenemos que concordar que no existen sociedades ajenas al mito; de hecho, todas las empresas históricas que se han dedicado a destruir 0 , al menos, a desarticular el sistema de mitos vigente en una sociedad se han realizado en nombre de otro sistema de mitos, el cual se considera como superior. Parece-como si toda colectividad humana estuviera incapacitada estructuralmente para funcionar, o de tener valores, sin poseer una noción -ya sea precisa o difusa- de lo que Laplantine llama la "experiencia de lo sagrado". La propuesta de este autor contradice de cierta manera los postulados de Godelier anteriormente mencionados de que el hombre ha forjado representaciones. $y_{\text {L }}$ les ha atribuido poderes sobrenaturales.

Así, al llamar "sobrenaturales" a las proyecciones míticas de los pueblos sin historia, se mistifica su pensamiento. Los grupos humanos construyen una noción de lo sagrado no porque sientan miedo o porque no puedan controlar esas potencias superiores, sino porque, para que una sociedad exista, es necesario que el mundo-signifique-algo,-que el_universo_tenga un sentido que por sí mismo no posee;-_con tal noción-de-sagrado son capaces de "metamorfosear-el-caos-inicial-y-siempre "inocente', como dice Nietzsche, en cosmos significante",--es-decir, de cargarlo de "una espesa densidad simbólica, rica y ambivalente al infinito"' (Laplantine, 977:56).

Cassirer insiste en que el mundo del hombre es un mundo enteramente simbólico, :y .eso quiere decir_que .el hombren no está nunca frente a la realidad, que no puede verla directamente sino siempre a través_de la mediación de los componentes del aparato simbólico:- lenguaje, arte, mito, religión-etc. Toda forma de vida humana -o lo que es lo mismo, cultural- en toda su riqueza y diversidad es simbólica..Este concepto de lo simbólico ha sido estudiado de manera especial por Lévi-Strauss, quien postula que hablar de mundo simbólico es lo mismo que hablar de un mundo construido con 
signos, y que es imposible la existencia de signos sin orden: "hablar de reglas y hablar de significado es hablar de la misma cosa"... (Lévi-Strauss, 1978:12). Si el criterio básico es el de cultura, importa entonces precisar cómo entiende esta noción: desde su libro sobre las estructuras del parentesco ya establecía que la distinción entre un proceso natural y un proceso cultural es la ausencia o presencia de reglas, puesto que "en todo lugar donde se presente la regla, sabemos que estamos en el estado de la cultura". En la naturaleza se reconoce lo universal, pues lo constante en todos los hombres escapa al dominio de las costumbres e instituciones por las cuales se distinguen los grupos humanos. Existe, por tanto, un doble criterio: la norma y la universalidad para distinguir lo cultural de lo natural; todo lo universal en el hombre corresponde al orden de la naturaleza y se caracteriza por la espontaneidad, mientras que todo lo que está sometido a normas pertenece a la cultura y presenta los atributos de lo relativo y particular. El problema es, entonces, cómo pasar de un dominio al otro; Lévi-Strauss recurre a los padres de la sociología, Mauss y Durkheim, para encontrar el eslabón entre naturaleza y cultura. Durkheim proponía tratar los hechos sociales como cosas, y sostenía que tales hechos sociales sólo podían explicarse por referencia a hechos sociales previos. Si las cosas fueran tal y como lo sostiene Durkheim, entonces no podría existir el mencionado esłabón, puesto que nada que no fuera social podría preceder a la sociedad; es decir, para él, lo social no proviene de lo natural sino de lo social mismo. Mauss, por su lado, considera los fenómenos sociales no en función de las normas de una sociedad, o en términos de contenido, por ej., sistemas de valores, sino que los analiza según su forma: así, un sistema social-no funciona_por las normas que lo_gobiernan, sino que es más bien una estructura, un conjunto de relaciones lógicas, cuya propia necesidad interna determina las normas, y no a la inversa. Con base en la propuesta de Mauss, LéviStrauss postula un estado natural necesario para la aparición de lo social. Podría denominarse hecho social natural un hecho 
que fuera universal en todas las sociedades, es decir, que manifestara el rasgo esencial de la cultura —la arbitrariedadpero que tuviera la marca de lo natural -lo necesario. Si es posible encontrar en todas las sociedades un mismo principio cultural, éste tiene que ser natural. Lévi-Strauss lo encuentra en el campo del comportamiento sexual: la sexualidad es natural, pero se vuelve cultural si se realiza sobre la base de una norma, y ésta es la prohibición del incesto; - esta regla es la que "retiene en la naturaleza aquello que es susceptible de superarla; por tanto es una regla que se encuentra en el umbral de la cultura, en la cultura y en cierto sentido es la cultura"- (Lévi-Strauss, 1983:44).

Benveniste, en consonancia con Lévi-Strauss, considera la cultura como un fenómeno enteramente simbólico, lo que es lo mismo, semiótico. La cultura conforma ese aparato que establece la relación entre el hombre y el mundo y entre el hombre y los demás. hombres,-ya que no existen vínculos naturales, inmediatos y directos. El mito es, entonces, uno de los componentes del aparato mediador.

Para entender el aspecto de finalidad que Lévi-Strauss asigna al mito, tenemos que ver las diferencias que separan su pensamiento de los que Malinowski y Lévi-Bruhl. Frente a la concepción funcionalista del primero —según la cual, si un grupo social está determinado por las necesidades de subsistencia o sexuales o de cualquier otro tipo, entonces es posible explicar sus instituciones sociales, sus mitos, etc. Lévi-Strauss afirma que el pensamiento de los miembros de las sociedades sin escritura es o puede ser, en muchos casos, desinteresado; esto es, que "están moviclos por una necesidad o deseo de entender el mundo a su derredor, su naturaleza y su sociedad" (1978:16). Frente a Lévi-Bruhl — quien piensa que la diferencia básica entre el pensamiento que él llama "primitivo" y el pensamiento moderno es que el primero está totalmente determinado por representaciones emotivas y místicas mientras que el segundo es racional- Lévi-Strauss sostiene que el pensamiento primitivo es capaz de operaciones intelectuales; es de- 
cir, que para lograr sus fines o satisfacer sus deseos "procede por medios intelectuales, exactamente como un filósofo, y en ciertos casos, como lo haría un científico" (Ibid). Hay, no obstante, una diferencia respecto al pensamiento científico, porque la finalidad del pensamiento primitivo es lograr a través del camino más corto una comprensión general del universo; más bien, no una comprensión general, sino total: es una manera de pensar que implica que si uno no entiende la totalidad, no puede entender las particularidades.

Esta búsqueda de la totalidad es distinta del modo científico de conocer sobre todo porque no alcanza su objetivo, puesto que "el mito es incapaz de dar al hombre más poder material sobre el entorno", aunque sí pueda dar a los hombres "la ilusión de que pueden entender el universo, que de hecho lo entienden" (Ibid:17). Otra finalidad que asigna es asegurar "tan estrechamente como sea posible _obviamente es imposible el cierre total- que el futuro permanezca fiel,al. presente y al pasado" (Ibid:43). Finalmente, en la última sección del cuarto volumen de Mitológicas, da otra pista acerca del papel de los mitos: son respuestas temporales y locales a los problemas planteados por los"ajustes realizables y las contradicciones imposibles de superar (1976:568). En síntesis, el mito sirve para proporcionar un conocimiento de la realidad — falso o verdadero, pero eso es ya otro problema-, sirve para resolver imaginariamente problemas irresolubles desde una perspectiva real, y, finalmente, sirve para asegurar la estabilidad social y política. Si observamos cuidadosamente estas funciones, veremos que son exactamente las mismas que se le asignan a esa noción vaga que se denomina ideología.

Pero no solamente pueden captarse semejanzas entre mito e icleología, sino también con la religión, con el arte, con la literatura y, en general, con todos los campos de Io simbólico. Parece importante detectar estas similitudes, pero no podemos contentarnos con la determinación de la proximidad del género sino que sería necesario precisar la diferencia específica. 
Dejemos por un momento esta reflexión para examinar un caso concreto de la funcionalidad del pensamiento mítico.

Los hombres de los siglos xI y xrr, por ejemplo, se sentían completamente aplastados por el misterio, dominados por un mundo desconocido que su mirada no podía examinar puesto que este mundo se extendía a un dominio que estaba más allá de la apariencia. En esta sociedad está vigente y operando en toda su plenitud el mito de la realeza; de hecho, como señala Duby, este mito es una de las características definitorias de la mentalidad medieval (Duby, 1983:2I). La sociedad humana se concibe entonces como un reflejo de la Ciudad de Dios, y ésta sólo puede verse a través del cristal de la monarquia: la figura del rey, modelo de la perfección terrestre, estaba en la posición más elevada dentro de la construcción-mental que dạba orden al_universo.-Descle la Alta Edad media, los reyes carolingios tenían la misión de dirigir la guerra, pero también poseían otra función más misteriosa: ser mediadores entre su pueblo y los dioses; de su mediación_dependia la felicidad de todos. Esa propiedad les era otorgada por la divinidad misma por filiación, puesto que por sus venas corría sangre divina; por tanto, la Iglesia situaba al Rey en el seno de las jerarquías sobrenaturales; su autoridad "emanaba de su carácter sobrenatural y su ministerio significaba ante todo, tal como lo celebraban los laudes regiae, la conciliación de dos mundos, el visible y el invisible, y la armonía cósmica entre el cielo y la tierra" (Duby, 1983:23). De Ia misma manera, se concibe a Dios como un rey: cuando san Anselmo quiere describir el mundo invisible, lo hace poniendo a los ángeles como vasallos que han recibido feudos de parte de Dios. Los monjes se saben guerreros que en cada uno de los castillos esperan recompensa por combatir; también el cristiano común espera protección de Dios de los peligros del mundo, y su finalidad es alcarnar el Paraíso, el feudo eterno: "Todos los hombres perciben su vida terrestre como una provincia invadida que deben defender; su honor los obliga a devolverla intacta a su Señor. 
En el día del Juicio Final, pondrán en una balanza su coraje y sus debilidades" (Ibid:66).

Lo más notable de todo es que la estructura monárquica no es ya funcional: desde inicios del siglo xI empieza a manifestarse la presencia de nuevas estructuras sociales en las cuales el poder del rey es cada vez menor. Este fenómeno es posible explicarlo por un lado por las vastas extensiones de los territorios, por el otro, por la presencia constante de invasores. De hecho, lo que parece de difícil comprensión es más bien cómo llegaron los reyes a dominar efectivamente y a conservar la unidad. La autoridad del soberano estaba cimentada en la guerra permanente y en la conquista ininterrumpida; por tanto, si dejan de realizarse las excursiones militares, con sus botines y recompensas, el Estado empieza a desintegrarse; con ello los pequeños príncipes regionales empiezan a adquirir poder puesto que parecen los únicos capaces de hacer la paz, de enfrentarse a los ataques invasores. Desde la perspectiva del pueblo, la seguridad no dependía ya del rey sino de los señores; en la vida cotidiana, todo el prestigio y el poder se trasladó a los jefes locales, a los duques y a los condes. Pero en el nivel de las representaciones míticas, el rey seguía estando presente, seguía viviendo en las conciencias, porque era la única manera de conciliar lo desconocido con lo conocido, lo oculto con lo visible. El mito de la realeza, en resumen, funciona como un medio de explicación al mismo tiempo que como un medio de asegurar la estabilidad social y política. Para usar las palabras de Louis Marin, el relato mítico "reasume una historia, un pasado, un tiempo anterior incluso al tiempo para dotarle su ritmo y su orden: hace, por medio de la recitación de su historia simbólica, la historia del grupo que se relata por y en ella; dicho de otro modo, explica o hace comprensible lo que, sin él, permaneceria opaco, angustiante, peligroso, en la experiencia vivida y la conducta actuada de una insuperable antítesis original [...] Por medio de esta puesta en movimiento de las contradicciones originarias de la sociedad, se hace ser y se otorga su historia contando 
la historia simbólica de las contradicciones en el tiempo de la palabra" (Marin, 1976:45). En otros términos, al contar este relato, hace existir la historia de la sociedad; al mismo tiempo, "por medio del sistema abierto y no obstante recorrible de las correspondencias de cada unidad discursiva en los diversos planos de la realidad natural, cósmica [...], etc., constituye el saber explicativo del mundo de esta sociedad, el conjunto significante que lo ordena y regula" (Ibid:46).

La cultura medieval -es decir, la sociedad de Europa occidental durante el periodo comprendido entre los siglos xI $y$ xrv- ofrece unà visión muy clara de la interrelación entre mito, fiesta, arte, rito, religión, en, fin, entre todos los componentes del aparato simbólico, al grado que en ocasiones es imposible distinguir sus especificidades. Lotman habla de la medieval como de una cultura de un alto grado de semioticidad, es decir, que da carácter de signo a todo, donde-lo significativo es índice de existencia: el no signo no existe. La concepción de mundo medieval se basaba en "la separación de la esencia real de los_fenómenos de su..esencia sígnica", y cualquier forma de actividad,..."para ser un hecho con valor social, tenía que transformarse en un ritual. El combate, la caza, la diplomacia - la administración en general-, el arte exigían un ritual" (Lotman, 1979:46). En este modelo la función del. signo era sustitutiva: el sustituto era el contenido y el sustituyente la expresión; por tanto, el sustituyente no tenía valor autónomo sino que recibía sulvalor según el Iugar jerárquico de su contenido en el modelo del.mundo-- Por otro -lado,-la relación entre parte-y todo asume un aspecto muy especial: la parte no es una fracción del conjunto sino su símbolo: "puesto que el plano del contenido de todo el mundo en su conjunto y de cada valor suyo cultural en particular pertenece a las esencias inconmensurables e indivisibles, cualquier división interesa solamente al plano de la expresión. Por ello, desde el punto de vista del contenido, la parte es equivalente al todo. En cambio, en la unidad del contenido y de la expresión la parte no entra en el todo sino que lo representa. 
$\mathrm{Y}$ puesto que en este sistema el todo es signo, la parte no es fracción sino que es un signo suyo, signo del signo" (Ibid). Esto tiene consecuencias para la concepción del individuo: el sujeto jurídico o religioso o moral no era el individuo sino los organismos corporativos; la presencia o ausencia de derechos dependía de la pertenencia o no pertenencia a un grupo; "cuanto más importante era el grupo del que formara parte el hombre, tanto más alto era su valor personal. EI hombre, como tal, no tenía ningún valor personal, ni gozaba de derechos personales" (Ibid:48).

El universo aparece al hombre medieval como un bosque lleno de misterios. Dios está oculto en medio de la espesura, pero su presencia se adivina por medio de vestigios; Dios "permite que se perciban las huellas de su mano y, por tanto, seguir su pista a condición de tener mucha paciencia y mucho amor" (Duby, 1983:104). Para aprender a conducirse en ese bosque donde la naturaleza encierra al hombre, éste debe poder desenredar la compleja madeja de símbolos con los que está tejido.

Si el hombre tenía tanto temor de lo invisible, le eran necesarios ritos y sacramentos para vincularse con lo sobrenatural; gracias a tales ritos colectivos, a la participación de los misterios, el hombre podía superar su naturaleza. Para captar lo imperceptible necesitaba de lo que hoy llamamos arte. Las obras artísticas se ubican en esa zona del comportamiento humano en la cual se manifiestan ciertos gestos aparentemente gratuitos, como una forma de compensar esos otros gestos impuestos por la necesidad de supervivencia. La gratuidad es aparente porque, como dice Duby, "la fiesta y el arte -que constituye el elemento superior de la misma- son operaciones equilibrantes, por tanto igual de necesarias que las que pretenden compensar, y no más libres. Las obligaciones de un ritual las regulan estrictamente" (1981:14). Tales gestos son afirmaciones de poderío; con ellos el hombre sale de sí mismo, se crece, sueña con dominar a los otros por el esplendor y la magnificencia. Por ello la obra artística es primordialmente 
objeto de adorno y de alarde. Pero también es exceso, desbordamiento, y por tanto establece vínculos con lo sagrado. Tanto la fiesta como la obra de arte son tentativas de transgresión de los límites que separan el mundo visible del invisible; y tal transgresión se consuma cuando logran hacer evadir al hombre de su realidad cotidiana, aun cuando sea por un instante. Là fiesta "renueva también el orden social ajustándolo por un momento a ese orden subyacente, enmascarado, inmaterial, que el mito narra $y$ del que el ceremonial brinda representación" (Ibid: 15).

La obra de arte surge de la oscuridad hacia el encuentro de la luz, de la más sensible manifestación de lo divino; de allí la identificación de lo bello con lo luminoso y lo brillante. Lo bello está unido a lo verdadero y a lo puro. Los metales y piedras preciosas ejercen entonces una gran fascinación, y la orfebrería es la actividad artística fundamental. Pero no hay que olvidar que su valor no es intrínseco sino que es en tanto que representa algo valioso, en este caso su participación de lo divino: el contenido de un valor religioso o moral requiere una expresión ornamentada; no se atribuye fuerza independiente a lo material del signo, sino que es una potencia reflejada. La obra de arte es, pues, un signo, y la atención del hombre medieval_es_atraída hacia_la relación_entre expresión y contenido; de ella Lotman nos señala algunas características: a) la expresión es siempre material, el contenido es siempre ideal; b) la relación entre ambos es de semejanza; es decir, se trata siempre de signos icónicos; de allí que se haya utilizado tanto la imagen del espejo tanto para la materia, en cuanto - plano de expresión del signo, cuyo contenido es el espíritu, como para la representación icónica" (Lotman, 1979:52); y c) la relación entre expresión y contenido no es arbitraria sino natural: es eterna y establecida por Dios; por ello, "el escritor que escribe un texto, el artista que pinta un cuadro, no son creadores sino simplemente mediadores, a través de quienes se da la expresión inherente al contenido_mismo" (Ibid).

Según Duby, la obra medieval que ahora consideramos ar- 
tística, ejercía tres funciones: primero, daba a las ceremonias sagradas una ornamentación, un decorado que las sacaba del espacio-tiempo ordinariós. Rodeaba los ritos cristianos de esplendor, manifestaba la omnipotencia de Dios con los mismos signos de poder que los soberanos terrestres. Segundo, la obra era sacrificio, consagración de una parte de las riquezas. Esta ofrenda tenía dos fines: de glorificación (por lo precioso del material, por la labor para hacer más pura y verdadera la materia, y por la belleza que manifestaba como señal de perfección; con todo ello se rendía alabanza al Greador) y de captación de benevolencia (como todo don, exige un contradón: la obra de arte, al dar gracias, pretende atraer nuevas gracias, a que el beneficiario devuelva con creces lo recibido). Tercero, la obra es un emblema, una ayuda para percibir_los_misterios del universo; a través de esta tercera función, la obra de arte sobrevive a la fiesta y se instala en la permanencia. La obra artística, a través del entrelazamiento de signos visibles, apunta hacia "la enseñanza ininterrumpida de aquello que los ritos habian representado un instante por gestos, de lo que el relato mítico -en este caso, la historia de la salvaciónhabía enunciado con palabras. Y lo hace por medio de imágenes; alimentando lo imaginario. Reflejo de este mundo, prefigura el más allá, ayuda al espíritu a. desembarazarse de las brumas del presente, lo atrae hacia perfecciones inactuales. Los arrebatos fugaces de la fiesta tienen valor de mediación. La obra de arte, que los prolonga y los prepara, también. Se propone al hombre como el instrumento dócil de un 'exceso', como una salida siempre abierta para evadirse de lo que hay de constringente y empobrecedor en el curso de la vida" (Duby, 1981:17).

Esta tercera finalidad de la obra de arte es compartida_con el mito y con el rito, puesto que es entrelazamiento de signos, producción de sentido no consumible, no perecedero. Si en la sociedad medieval es posible encontrar estas correspondencias y similitudes en todos los dominios de lo simbólico, es decir, en todo el campo de la cultura, eso no es tan evidente en las 
sociedades modernas, ya que no poseemos una noción clara de las finalidades del arte ni estamos ante una distancia suficiente para definir los mitos que nos rigen; esto lo ha expresado claramente Laplantine cuando dice que, "a partir del momento en que un grupo social o, incluso, una sociedad integra, evoluciona dentro de un mito rector, regulador e instrumento absoluto de explicación del mundo, ese grupo social o esa sociedad global se encuentra en la imposibilidad manifiesta de tomar alguna distancia crítica con respecto a lo que ella misma implanta apologéticamente como matriz básica y exclusiva de significaciones" (1977:54). Esa misma incapacidad de comprender el mito a la que nos hemos referido al inicio de esta nota, proveniente de una postura racional cartesiana, es también el origen de la separación en nuestro pensamiento moderno del mito y del arte, o del mito y la literatura en particular; estamos acostumbrados a considerar mito y literatura como dos esferas autónomas, que obedecen a imperativos diferentes $y$ que cumplen finalidades también diferentes. La tradición racional de Occidente nos ha llevado a considerar como privilegiados, en los esquemas de pensamiento o en los modelos del mundo, a los conjuntos de ideas en los que se destaca su carácter sistémico; también tiende a privilegiar los aspectos intelectuales de las producciones o manifestaciones de tales modelos del mundo, como si fueran los más eficaces, pero no hay nada que indique, a priori, una relación entre el grado de racionalidad y la eficacia.

La experiencia nos indica que es necesario considerar que las determinaciones de lo simbólico no agotan la sustancia del símbolo puesto que queda siempre un margen de indeterminación a lo cual hemos denominado imaginario- Lo-simbó7ico, dice Gastoriadis, ${ }_{;}$comporta-casi-siempre-un-componente racional -o real-, es decir, aquello que es indispensable para pensarlo o para actuarlo; pero este componente está unido indisolublemente con lo imaginario. Si pensamos que tanto el arte, la religión, el mito, etc., son instituciones de la sociedad, veremos entonces que éstas no pueden reducirse a lo simbólico, 
aunque no puedan existir más que dentro de lo simbólico: "una organización dada de la economía, un sistema de derecho, una religión, existen socialmente como sistemas simbólicos sancionados" (Castoriadis, 1983:201). La fuente de las instituciones es el imaginario, que debe estar asociado con lo simbólico, puesto que de otra manera la sociedad no hubiera podido "reunirse", y con lo económico, pues sin ello la sociedad no sobreviviría.

Según LeGoff, para tratar de comprender cómo funciona una sociedad y cómo cambia y se transforma, es necesario mirar por el lado de lo imaginario (1983:11). No podremos describir y comprender las sociedades solamente en su carácter funcional, sin tomar en cuenta las cadenas de sentido que escapan a la funcionalidad, incluso a las cuales ésta se encuentra subordinada. Tampoco es posible ver la religión, el arte o el mito simplemente como redes simbólicas; es cierto que forman redes simbólicas, pero remiten a cosas distintas del mero simbolismo, puesto que queda por resolver la cuestión cle por qué tales símbolos y no otros. Así como lo funcional toma el sentido de lo exterior de sí mismo, el simbolismo se refiere a algo que no está en lo simbólico; "este elemento que da a la funcionalidad de cada sistema institucional su orientación específica, que sobredetermina la elección y las conexiones de las redes simbólicas, creación de cada época histórica, su manera singular de vivir, de ver y de hacer su propia existencia, su mundo y sus propias relaciones; este estructurante imaginario [...] fuente de lo que se da cada vez como sentido indiscutible e indiscutido, soporte de las articulaciones y de las distinciones de lo que importa y de lo que no importa, origen del exceso de ser de los objetos de inversión práctica, afectiva o intelectual, individuales o colectivos $[\ldots]$ no es otra cosa que lo imaginario de la sociedad o de la época considerada" (Castoriadis, 1989:252).

Este componente imaginario es, entonces, un conjunto de representaciones creado por toda sociedad por medio del cual se reproduce e identifica consigo mismo al grupo, clistribuye 
las identidades y papeles, y expresa las necesidades colectivas y los fines; gracias a él, las sociedades, sean modernas o tradicionales, se dan nombre y se fijan sus normas y valores.

Desde esta perspectiva, todo mito es un relato que proporciona una red de sentido con la cual se explica el orden_del mundo; los mitos de origen, por ejemplo, sirven para que el mundo físico encuentre su-razón...de ser.y...su. finalidad....Allí están de manera explícita los fines de la vida cotidiana. El relato mítico, dice Ansart, sitúa la finalidad suprema de la vida cotidiana en la realización del mito, "en la fidelidad a los modelos y la representación renovada de su sentido colectivo mediante el rito y la ceremonia". Arte, mito, rito, ceremonia, fiesta, todos ellos como partícipes de lo imaginario: el rito justifica "los ciclos de la vida colectiva, los diferentes momentos de la vitalidad común con sus fases de latencia y regeneración. La fiesta del retorno a los orígenes expresa el momento supremo de la adecuación de lo vivido a las significaciones. En ellos se somete a prueba el sentido universal cuya repetición asegura, mágicamente, la regeneración total" (Ansart, 1983:19).

Ninguna sociedad puede existir si no organiza la producción de su vida material y su reproducción en tanto que sociedad; pero esta organización no está determinada por leyes naturales o por consideraciones racionales o funcionales, sino que en el margen de indeterminación se sitúa lo más importante: que el mundo se capta de-una-determinada_manera, que se le impone siempre un sentido gracias_a que_se_operan-ciertas distinciones correlativas a lo que vale y lo que no vale $-y$ entre lo que se debe y no-se-debe-hacer_o lo_que_se-puede y no se puede--Lo-imaginario-de-una-sociedad-se-manifiesta en la constitución de un universo - de-significaciones-y-sobre ellas se articula el mundo_de lo_social; de_allí que_no_podamos prescindir de la categoría de lo imaginario, pues es ella la que nos permite reflexionar sobre preguntas como las siguientes: dentro de las prácticamente infinitas estructuras simbólicas posibles, ¿qué es lo que especifica un sistema sim- 
bólico, establece las relaciones canónicas prevalentes, orienta hacia una de las incontables direcciones posibles todas las metáforas y metonimias abstractamente concebibles? Es necesario un factor unificante que proporcione los contenidos y los entreteja con las estructuras simbólicas; este factor, dice Castoriadis, no es lo real, puesto que cada sociedad ha constituido su propia realidad; tampoco es lo racional, puesto que la historia no ha sido una pura progresión hacia la racionalidad; ese factor es "Ia creación imaginaria propia de la historia, aquello en y por lo que la historia se constituye para empezar" (Ibid:278).

Como toda producción cultural, el mito participa tanto de lo simbólico como de lo imaginario; es éste uno de los_grandes atolladeros con que nos encontramos a la hora de querer-pre= cisar lo que son los textos literarios o artísticos en general, los ritos religiosos, las ceremonias o los mitos. En tanto que participa de lo simbólico, el mito asigna un lugar en la jerarquía, proporciona un modelo de las relaciones de autoridad que conviene respetar para asegurar la circulación. y producción de sentido, para asegurar la separación entre lo sagrado y_lo profano. La necesidad de repetir el rito, la fiesta, la recitación del mito, obedece-a que el sentido debe ser actualizado incesantemente para que la vida colectiva conserve su coherencia; lo que se renueva con la repetición no es sólo el sentido global sino también el esquema de legitimación que asigna derechos y deberes. Es decir, el mito no es solamente-estructura de sentido sino también un instrumento de regulación-social,_las.normas que mantienen un sistema de estratifiçación;-en resumen, el conjunto de los mitos de una colectividad sirven tanto para asegurar la donación de señtido, como para explicar el mundo de las cosas y de los hombres, y para imponer un sistema de jerarquías y poderes.

Pero como manifestación de lo imaginario, los mitos dan a la colectividad y a la sociedad un ser, el cual se define en relación a un "nosotros" y, por tanto, a un "los otros". Este nosotros es, antes que nada un nombre; es claro que tal nombre 
es un símbolo en la medida en que designa a los que pertenecen a la colectividad; pero también es otra cosa, es un elemento constituyente del individuo $y$, por ello, remite a significaciones que sólo podemos denominar imaginarias. Además del nombre, en la persona del rey es también donde se materializa, donde se define la sustancia de la colectividad como existente. Tanto en el nombre como en la persona del rey o del gobernante, entre otras cosas, podemos observar la imagen que los miembros de una sociedad tienen de sí mismos, de los otros, del mundo en general; en este conjunto, que podemos llamar modelo del mundo, encuentran un lugar los objetos y los seres que importan para la vida social. En el modelo deI mundo está presente la selección de objetos, acontecimientos, etc., que encarnan lo que para tal sociedad tiene sentido y valor. Pero también están presentes las aspiraciones y deseos más ocultos. Por ello el mito no es una pura realización ilusoria de lo que la realidad impide, sino que tendremos que verlo como una forma de enunciar nuestra esperanza: el mito es el testimonio "de que el hombre no ha sido arrojado a un espacio incoherente y a una temporalidad ilimitada. Con el advenimiento del pensamiento mítico, se decir, del pensamiento humano, los puntos de referencia dejan de ser imprecisos, y el grupo humano se vuelve capaz de orientarse en el mundo, moldeándolo según las exigencias de un proyecto que él mismo se ha fijado. Sin ese pensamiento, no tendríamos. razón alguna de virir ni de morir" (Laplantine, 1977:57).

\section{REFERENCIAS}

Ansart, 1983. Pierre Ansart, Ideologia, conflictos y poder, México: Premiá, 1983.

Castoriadis, 1983. Cornelius Castoriadis, La institución imaginaria de la sociedad, Barcelona: Tusquets, 1983.

Duby, 1981. Georges Duby, San Bernardo y el arte cisterciense, Madrid: Taurus, 1981.

Duby, 1983. Georges Duby, Tiempo de catedrales. El arte y la sociedad, 980-1420, Barcelona: Argot, 1983. 
Godelier, 1980. Maurice Godelier, Economia, fetichismo y religión en las sociedades primitivas, Madrid: Siglo XXI, 1980.

Laplantine, 1977. François Laplantine, Las voces de la imaginación colectiva, Barcelona: Granica, 1977.

LeGoff, 1983. Jacques LeGoff, Tiempo, trabajo y cultura en el Occidente medieval, Madrid: Taurus, 1983.

Lévi-Strauss, 1976. Claude Lévi-Strauss, Mitológicas IV. El hombre desnudo, México: Siglo XXI, 1976.

Lévi-Strauss, 1978. Claude Lévi Straus, Myth and Meaning, University of Toronto Press, 1978.

Lévi-Strauss, 1983. Claude Lévi-Strauss, Estructuras elementales del parentesco, México: Paidós, 1983.

Lotman, 1979. Jurij M. Lotman y Escuela de Tartu, Semiótica de la cultura, Madrid: Cátedra, 1979.

Marin, 1976. Louis Marin, Utópicas. Juegos de espacios, Madrid:

Siglo XXI, 1976. 